\title{
Treating the severely diseased tricuspid valve: Is spiral suspension of the papillary muscles the answer?
}

Oliver J. Liakopoulos, MD, and Thorsten Wahlers, MD

\author{
From the Department of Cardiothoracic Surgery, Heart Center, University of Cologne, Cologne, Germany. \\ Disclosures: Authors have nothing to disclose with regard to commercial support. \\ Received for publication March 18, 2018; accepted for publication March 21, 2018; available ahead of print May \\ $3,2018$. \\ Address for reprints: Oliver J. Liakopoulos, MD, Department of Cardiothoracic Surgery, Heart Center of the Uni- \\ versity of Cologne, Kerpener Strasse 62, Cologne 50924, Germany (E-mail: oliver.liakopoulos@uk-koeln.de). \\ J Thorac Cardiovasc Surg 2018;156:653-4 \\ $0022-5223 / \$ 36.00$ \\ Copyright (C) 2018 by The American Association for Thoracic Surgery \\ https://doi.org/10.1016/j.jtcvs.2018.03.073
}

The optimal surgical management of the functionally diseased tricuspid valve is still a matter of controversy, ${ }^{1-3}$ and it is complicated by the traditionally poor clinical outcomes of tricuspid valve surgery (TVS). A recent trend analysis of the Society of Thoracic Surgeons database, with more than 54.000 patients undergoing TVS between 2000 and 2010 in North America, showed that most TVS procedures $(85.7 \%)$ were performed as concomitant procedures, with approximately $80 \%$ of patients undergoing simultaneous mitral valve surgery at the time of TVS. ${ }^{4}$ Although the rate of tricuspid valve reconstruction relative to replacement is constantly increasing $(88.9 \%$ vs $10.2 \%$ ), the operative mortality after TVS is still substantial, with a $9.6 \%$ unadjusted mortality reported in the Society of Thoracic Surgeons database analysis. ${ }^{4}$

A recent study from David and coworkers ${ }^{5}$ emphasizes that the need to address the functionally diseased tricuspid valve at the time of mitral valve surgery is uncommon $(11.8 \%){ }^{5}$ and current guidelines recommend that the tricuspid valve should be addressed with an annuloplasty in the presence of (1) a moderate to severe tricuspid regurgitation (TR) or (2) a tricuspid annular dimension greater than $40 \mathrm{~mm}{ }^{6}$ A retrospective analysis by Chikwe and colleagues $^{7}$ from New York revealed that concomitant tricuspid annuloplasty at the time of mitral surgery in compliance with these recommendations resulted in a greater freedom from recurrent TR and, most importantly, facilitated long-term right ventricular (RV) remodeling. The echocardiographic data from the New York group suggest that elimination of relevant TR by tricuspid annuloplasty alone may indeed facilitate reverse remodeling of the right atrial and RV structure and function and improve long-term clinical outcomes of patients.

In this issue of the Journal, Eishi and coworkers ${ }^{8}$ present a novel repair technique for severe functional TR with leaflet tethering. In a case series consisting of 7 patients,

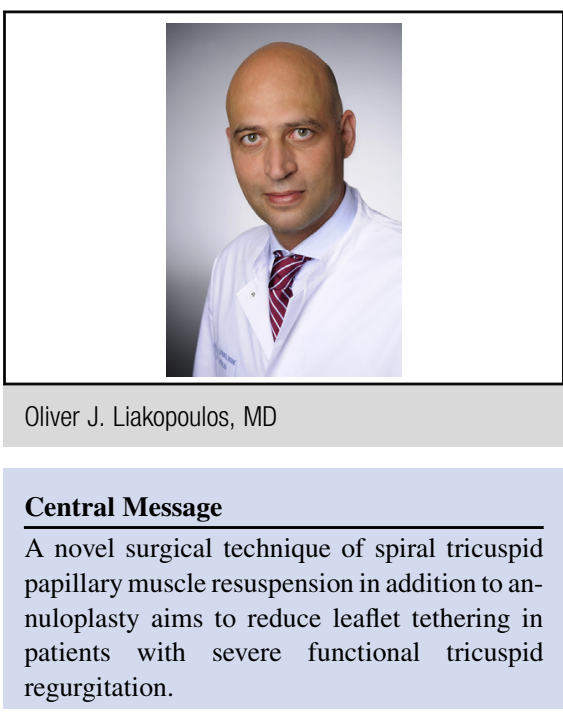

See Article page 649.

the anterior and inferior papillary muscles were approximated in a spiral fashion before annuloplasty (Figure 1 and Video 1 in their article ${ }^{8}$ ). Spiral suspension of the tricuspid subvalvular apparatus resulted in RV reshaping, thereby increasing leaflet mobility. One-year follow-up showed a significant reduction of RV diameter, pulmonary arterial pressure, and New York Heart Association functional class, and 3-dimensional echocardiographic imaging (Figure 3) confirmed durability of the anatomic repair.

Eishi and coworkers ${ }^{8}$ are to be congratulated for providing this novel surgical strategy for severe functional TR that not only addresses annular dilatation. Although reshaping the RV and reducing leaflet tethering by resuspension of the diseased subvalvular apparatus seems to be an intriguing and promising approach, several considerations need to be addressed. First, the exact anatomical and echocardiographic parameters need to be defined in more detail to discriminate patients who may benefit from the procedure. For instance, beyond the proposed leaflet tenting height $(>5.1 \mathrm{~mm})$ and area $(>0.8 \mathrm{~cm})$, other parameters as the height of the surface of coaptation and papillary muscle positioning may be predictive of the success of the repair. Second, the effectiveness of the adjunctive spiral suspension procedure relative to simple annuloplasty remains largely unclear in the report by Eishi and coworkers ${ }^{8}$ because of the absence of an adequately matched control group. Finally, the safety and durability of the proposed 
spiral suspension technique and its potential benefit relative to a simple annuloplasty need to be evaluated in a long-term period, far beyond the presented 12-month follow-up period. Consequently, more evidence from future studies is needed before a wider spread of the proposed spiral suspension technique into the surgical routine can be recommended.

\section{References}

1. Dion RA. Is the air in Toronto, Rochester, and Cleveland different from that in London, Monaco, Leiden, Genk, Milan, and New York? J Thorac Cardiovasc Surg. 2015;150:1040-3.

2. David TE, David CM, Manlhiot C. When is tricuspid annuloplasty necessary during mitral valve surgery? J Thorac Cardiovasc Surg. 2015;150:1043-4.

3. Gillinov M, Mick S, McCurry K, Navia J. The tricuspid valve: if it's not broken, don't fix it. J Thorac Cardiovasc Surg. 2017;154:108-9.
4. Kilic A, Saha-Chaudhuri P, Rankin JS, Conte JV. Trends and outcomes of tricuspid valve surgery in North America: an analysis of more than 50,000 patients from the Society of Thoracic Surgeons database. Ann Thorac Surg. 2013;96:1546-52; discussion 1552.

5. David TE, David CM, Fan CS, Manlhiot C. Tricuspid regurgitation is uncommon after mitral valve repair for degenerative diseases. J Thorac Cardiovasc Surg. 2017; 154:110-22.e1.

6. Nishimura RA, Otto CM, Bonow RO, Carabello BA, Erwin JP III, Fleisher LA, et al. 2017 AHA/ACC focused update of the 2014 AHA/ACC guideline for the management of patients with valvular heart disease: a report of the American College of Cardiology/American Heart Association task force on clinical practice guidelines. Circulation. 2017;135:e1159-95.

7. Chikwe J, Itagaki S, Anyanwu A, Adams DH. Impact of concomitant tricuspid annuloplasty on tricuspid regurgitation, right ventricular function, and pulmonary artery hypertension after repair of mitral valve prolapse. J Am Coll Cardiol. 2015;65: 1931-8.

8. Eishi K, Miura T, Matsumaru I, Tanigawa K, Obase K. Spiral suspension, a novel repair technique for severe functional tricuspid regurgitation. J Thorac Cardiovasc Surg. 2018;156:649-52 